Journal of the Scholarship of Teaching and Learning, Vol. 21, No. 3, October 2021, pp. 49-70. doi: 10.14434/josotl.v21i3.31178

\title{
Does Short-Term International Immersion have a Sustainable Impact on Teachers' Cultural Competence? Follow-up Interviews Eight Years After a Teaching Experience in South Korea
}

\author{
Kevin Oh \\ University of San Francisco
}

\author{
Natalie Nussli \\ University of Applied Sciences and Arts Northwestern Switzerland
}

\begin{abstract}
This qualitative study was conducted with teacher candidates studying in a Masters program at a university on the west coast in the United States. The main goal was to capture if immersion in a foreign culture and the short-term teaching of primary and secondary school students in South Korea had any sustainable impact on the participating teachers' perception of their cultural knowledge, competence, and awareness almost a decade after their immersion experience. The researchers interviewed four teachers who had participated in one of two immersion projects conducted in 2010 and 2011. A questionnaire on teachers' self-efficacy regarding culturally responsive teaching (modified from Chu \& Garcia, 2014) was administered prior to the interview giving the participants a tool to reflect on what it means to be a culturally responsive teacher and to self-assess their own cultural competence and teaching practices. Four themes emerged from the interviews, namely, perspective taking ability, relationships, teaching strategies, and cultural knowledge. The findings indicate that international immersion not only offers an effective way for pre-service teachers to receive intercultural training. It also has the potential to create transformative learning experiences by immersing students in cultural contexts unfamiliar to them. The findings from this study will be interesting to teacher educators who consider integrating international immersion projects into their teacher education programs.
\end{abstract}

Keywords: immersion programs; international field experiences; teaching abroad; study abroad; international practicum; transformative learning; diversity; culturally responsive teaching; culturally sensitive teaching; socially sensitive teaching; multicultural education; cultural awareness; cultural knowledge; professional growth; teacher education; teacher training; professional development

\section{Introduction}

International cross-cultural field experiences for pre- and in-service teachers have been associated with many positive outcomes, such as teachers' enhanced empathy and respect toward students with a culturally diverse background, greater self-confidence in teaching, better problem-solving skills, greater flexibility, a more inclusive approach to cultural differences, and increased intercultural awareness (Baecher \& Chung, 2020; Kambutu \& Nganga, 2008; Mahon \& Cushner, 2002; Malewski et al., 2012; Rodriguez, 2011; Walters et al., 2009).

Teacher candidates returning from international field experiences tend to be more appreciative of students' cultural heritage and more willing to use it as a valuable source to enrich the curriculum (Shedrow, 2017). According to Baecher and Chung (2020), these pre-service teachers are more skilled at comparing and contrasting the instructional approaches viewed at home and abroad, recognizing "the ways English may or may not be present in students' lives prior to coming to the US” (p. 42), reflecting critically on curriculum design, and making adjustments as needed. International field experiences have also been associated with an increased ability to connect with 
diversity, a better understanding of curriculum and pedagogy, and a higher interest in teaching diverse students (Malewski et al., 2012). Such field experiences are critical to becoming culturally responsive educators and are "most effective before a student teaching internship when combined with critical reflection that is connected to issues of equity and effective teaching research" (Vavrus, 2008, p. 54).

The short-term impact of teaching abroad programs appears to be well researched. However, most of the research on cultural immersion abroad was conducted with pre-service teachers (Baecher \& Chung, 2020) rather than in-service teachers. Kambutu and Nganga (2008), for example, conducted follow-up interviews with the U.S. American participants of a cultural immersion stay in Kenya. Indeed, the interviews conducted upon return indicated the potential for sustained acculturation. However, the lack of follow-up interviews at a later point in time did not allow for conclusive statements (Kambutu \& Nganga, 2008).

Investigating the long-term impact, rather than the short-term effects, of international immersion projects would provide a better understanding of the sustainability of these potentially transformative experiences and would reveal whether there were any shifts regarding curriculum integration and pedagogical practices (Malewski et al., 2012; Maynes et al., 2013). The literature about immersion abroad studies will benefit from investigations into how teacher candidates have transferred what they have learned during immersion into a real teaching context, that is, once they actually teach culturally and linguistically diverse students (Malewski et al., 2012) for an extended period of time.

Thus, the main purpose of this study was to explore whether the short-term immersion abroad had any sustainable impact on the participating pre-service teachers almost a decade earlier and if this experience has helped shape their teaching approaches. In this research study, cultural immersion abroad means being physically present for two to three weeks in another country with a different culture and interact intensely with the local community, including the teaching of English to young students.

\section{Literature Review}

The literature review starts by providing a brief introduction into culturally responsive teaching and the key competencies that educators should demonstrate. Next, the authors review the research on the opportunities that international immersion programs offer to provide transformative learning opportunities. Teachers' perspective taking ability and the notions of culturally and socially sensitive teaching, which are ingredients of culturally responsive teaching practices, are reviewed next. The review concludes with a summary of the two studies that the lead author conducted in 2010 and 2011 and which served as the foundation for the present follow-up study.

\section{Culturally Responsive Teaching}

Decades of research and scholarship have captured the history of culturally responsive teaching, which Gay (2013) defined as "using cultural knowledge, prior experiences, frames of reference, and performance styles of ethnically diverse students to make learning encounters more relevant to and more effective for them" (p. 49-50). Multiple frameworks for culturally responsive approaches have emerged from the pioneering work of Ladson-Billings (1995), Gay (2000), and Nieto (1994). Culturally relevant practitioners emphasize cultural referents to share knowledge and help students acquire skills. They empower students on multiple levels, namely, intellectually, socially, emotionally, and politically (Ladson-Billings, 1995) and they work consciously to develop commonalities among all the students (Ladson-Billings, 2009). Each framework or approach emphasizes a specific set of

Journal of the Scholarship of Teaching and Learning, Vol. 21, No. 3, October 2021. josotl.indiana.edu 
components (Muñiz, J. (2019).

Gay (2010) calls on culturally responsive educators to adjust their instructional approaches, to evaluate instructional materials critically, to embrace positive student-teacher relationships, to increase their self-awareness, and to embrace an asset-based view of students to support learning and maximize all students' academic success.

Also building on Ladson-Billings' (1995) seminal work, Villegas and Lucas (2002) posited six characteristics that culturally responsive teachers should embrace. These six strands include a sociocultural consciousness, an affirming attitude toward students from culturally diverse backgrounds, commitment and skills to act as agents of change, constructivist views of learning, willingness to learn about students, and commitment to culturally responsive teaching practices. They encourage teacher educators to critically evaluate their curricula and infuse practices and experiences into the programs that help teacher candidates become culturally competent teachers (Villegas \& Lucas, 2002).

However, today's educators feel underprepared to meet the needs of a diverse student population who might have "hundreds of languages and cultures" (Barba et al., 2019, p. 31). There is growing pressure on teacher educators to provide diversity experiences (Keengwe, 2010) so that teacher candidates can develop cultural knowledge, competence, and awareness needed to better support their students in their struggles to meet today's academic requirements and to help maintain and affirm their linguistic and cultural strengths (Barba et al., 2019).

It is the responsibility of teacher education programs to encourage future educators to become advocates for culturally responsive teaching approaches (Baecher \& Chung, 2020; Lucas \& Villegas, 2002; Malewski et al., 2012; Muñiz, 2019) and to develop the ability to recognize and accommodate the needs of a diversity of cultural groups (Trumbull et al., 2007). Pre-service teachers should graduate from a teacher training program with an acute vision of what it means to be culturally responsive, which goals should be pursued, how to achieve these goals, and how to adapt a curriculum to the needs of a particular group of students in a specific context (Villegas \& Lucas, 2002).

One of the essential components of teacher development is that teachers get training, guidance and opportunities to explore and understand the school experience of students with a culturally and linguistically diverse background (Baecher \& Chung, 2020; Villegas \& Lucas, 2002). Acquah and Commins (2017), for example, recommend first-hand cultural interactions, critical selfanalysis, structured field experiences with post reflections, writing autobiographies to promote cultural self-awareness, and discussions on diversity and culture to be included in teacher education programs. Given the impact of international immersion experiences, as outlined in the introduction, they offer the potential to help teacher candidates transform into culturally responsive educators (Malewski et al., 2012) by providing experiences that would otherwise not be possible in a traditional classroom-based learning environment (Kambutu \& Nganga, 2008).

There is a long list of key competencies that culturally responsive teachers should have:

Culturally responsive teachers (...) are regularly investigating sources that can increase the multicultural perspective of their teaching disciplines. Teachers also learn about the communities and cultures from which their students originate and try to incorporate those orientations and resources into daily instruction. Culturally responsive teachers are life-long learners of culture and its implications for teaching and learning in their particular settings. (Vavrus, 2008, p. 55)

Culturally responsive teachers take an inquiry stand and ask questions about who their students are, what they need, and how to draw on their own teaching strengths to tailor instructional

Journal of the Scholarship of Teaching and Learning, Vol. 21, No. 3, October 2021. josotl.indiana.edu 
strategies in a way that works for these students (Hammond, 2014). Culturally responsive teaching is mirrored in:

... an educator's ability to recognize students' cultural displays of learning and meaning making and respond positively and constructively with teaching moves that use cultural knowledge as a scaffold to connect what the student knows to new concepts and content in order to promote effective information processing. All the while, the educator understands the importance of being in a relationship and having a social-emotional connection to the student in order to create a safe space for learning. (Hammond, 2014, p. 15)

The ability to make instruction more responsive to the students' needs requires educators to take their students' perspectives. What it means to take someone else's perspective and why it is essential to culturally responsive teaching is explored next.

\section{Perspective Taking Ability}

The ability to take someone's perspective is among the key qualities that have been suggested to facilitate a culturally responsive teaching approach (Abacioglu et al., 2019). Perspective taking is the ability to perceive something from someone else's perspective (Moskowitz, 2005). Perspective taking manifests itself in teachers' respect and appreciation for students' individual and unique experiences, their flexibility in adapting curricula and instruction (Darling-Hammond, 2000; McAllister \& Irvine, 2002), and their efforts to maximize unbiased education (Rychly \& Graves, 2012). Teachers should be able to take their students' perspectives by switching from their own frame of reference to their students' frames of reference. Problematic frames of reference are "sets of fixed assumptions and expectations" (Mezirow, 2003, p. 58).

Abacioglu et al. (2019) hypothesized that higher perspective taking abilities and more positive multicultural attitudes both correlate with more frequent engagement in culturally responsive teaching practices. Their multivariate multiple regression analysis confirmed both hypotheses. They administered questionnaires about culturally responsive teaching practices, perspective taking abilities, and multicultural attitudes to Dutch primary school teachers $(\mathrm{n}=143$ ). Their findings indicate that higher perspective taking abilities and more positive multicultural attitudes are significantly associated with teachers' engagement in culturally and socially sensitive teaching.

Strengthening teachers' perspective taking abilities can happen in many ways. For example, providing regular exposure to texts written on and by culturally diverse authors; participating in the social worlds of one's students and of individuals from cultural communities other than one's own; engaging in critical dialogues with colleagues; and providing ample opportunities for introspection on one's emotions, attitudes, and responses to one's students and their families (Warren, 2017). Higher perspective taking abilities and more positive multicultural attitudes benefit all students regardless of their backgrounds (Abacioglu et al., 2019).

Culturally sensitive teaching and socially sensitive teaching, which will be briefly discussed next, are two separate but related components reflected in culturally responsive teaching approaches (Abacioglu et al., 2019).

\section{Culturally Sensitive Teaching}

Culturally sensitive teachers have the ability to adapt their teaching and the curriculum to better meet their students' individual differences related to cultural elements (Abacioglu et al., 2019). Some 
components of culturally responsive teaching have been associated with culturally sensitive teaching, for example, identifying the ways in which the school culture, including values, norms, and practices diverge from the students' home culture; "using the cultural background of my students to make learning meaningful", "revise educational materials to improve its representation of cultural groups" and "make use of examples that are relatable for students from culturally different backgrounds" (Abacioglu et al., 2019, p. 16, based on Siwatu, 2007).

\section{Socially Sensitive Teaching}

A socially sensitive teacher has the ability to accommodate individual student differences that are not necessarily related to cultural elements (Abacioglu et al., 2019). Some components of culturally responsive teaching have been associated with socially sensitive teaching, for example, "adjust instructions to cater to the needs of my students", "assessing whether my students rather work alone or in a group", "use a learning preference survey to obtain information on how my students prefer to learn", and "help students establish positive relationships with their classmates" (Abacioglu et al., 2019, based on Siwatu, 2007). Perspective taking ability was shown to be a strong predictor of culturally sensitive teaching and socially sensitive teaching. Thus, it has been recommended that teacher education programs emphasize perspective taking experiences (Abacioglu et al. 2019).

\section{Transformative Learning}

Transformative learning has been defined as "learning that transforms problematic frames of reference $(. .$.$) to become more inclusive, discriminating, open, reflective, and emotionally able to$ change", thereby prompting the "re-evaluation of identity, values and opinions" (Mezirow, 2003, p. 58). Dissonant experiences are needed to upset previous assumptions, for example, by teaching or observing teaching in other countries, comparing and contrasting lesson plans, or seeing teaching methods previously thought of as being 'unsuccessful' work out quite effectively in a different cultural context (Malewski et al., 2012). In a study by Baecher and Chung (2020), for example, teacher candidates were "struck by the innovative and adaptive ways local teachers utilized their limited resources and physical space" (p. 44) revealing a dissonance between their assumptions and reality, thereby offering a transformative learning opportunity. Studies on using pedagogies of discomfort as a framework for field experiences indicate that intentionally exposing teacher candidates to discomforting experiences helps them construct new understanding about the needs of underserved and culturally diverse communities (Lazar \& Sharma, 2016; Sharma et al., 2012). Trilokekar and Kukar (2011) define disorienting experiences as challenging cultural encounters causing feelings of discomfort.

Transformative learning happens when one is aware of one's frame of reference and critically evaluates it from different perspectives (Baecher \& Chung, 2020; Mezirow, 2003). Acquah and Szelei (2020), for example, recommend activities for teacher education programs that offer a potential for transformative learning, namely, activities that aim at exposing what is invisible about culture, challenging the pre-service teachers' status in society, reflecting upon which aspects of their home culture they are struggling with most, deconstructing "culturally hegemonic practices and negative stereotyping" (p. 169), rejecting the reproduction of practices devaluating cultural groups, challenging curriculum and practices that fail to reflect the cultural and linguistic diversity of the student population, and building new principles and values. These activities may offer a platform for transformative learning even without an immersive setting.

International field experiences have been associated with transformative learning experiences

(Lazar \& Sharma, 2016; Sharma et al., 2012) because the participants experience "disorienting

Journal of the Scholarship of Teaching and Learning, Vol. 21, No. 3, October 2021.

josotl.indiana.edu 
cultural situations" that are in conflict with "their existing cultural schemes" (Kambutu \& Nganga, 2008, p. 941). Transformative learning may happen as a result of the participants' reflection on the unfamiliar cultural experience. Thus, transformative learning has the potential to "promote cultural awareness, understanding and appreciation” (Kambutu \& Nganga, 2008, p. 942).

The present study builds on earlier work by the same authors exploring the potential of international learning experiences for pre-service teachers to be immersed in a foreign culture, broaden their cultural awareness, and build cultural competence, with the potential of experiencing transformative learning. The ultimate goal was to provide these teacher candidates an experience that would help them become better teachers for culturally and linguistically diverse U.S. student populations. These two earlier projects, which were conducted in South Korea in 2010 and 2011, are briefly summarized in the next section to provide meaningful background about the context, the research goals, the participating teacher candidates, and the findings.

\section{Immersion Programs in South Korea}

Creating challenging and eye-opening experiences for U.S. teacher candidates. In the year 2010, the lead author conducted an exploratory case study to investigate the impact of a short-term international experience on pre-service teachers' global perspectives (Oh \& Nussli, 2014). These teachers ( $\mathrm{n}=5$ ), all female graduate students from a university in the U.S., were fully immersed in Korean culture for three weeks while teaching English to primary and secondary students in South Korea. They were also exposed to traditional Korean culture via outings, meals, and social gatherings.

Before traveling to South Korea, they received basic training that would prepare them for the communicative and cultural differences. As a Korean-American, the lead author trained the participating teachers in the U.S. prior to their departure about cultural differences and mannerisms specific to the Korean culture. One such difference is Koreans' preference for a lecture style format of teaching and unfamiliarity with classroom settings where students share thoughts and engage in collaborative learning activities. While the U.S. teachers were instructed to provide more interactive opportunities in classrooms, they were also expected to be sensitive toward Korean students' lack of familiarity with interactive class discussions. During their three-week immersion in South Korea, the participants' experiences and perceptions were consistently captured using a variety of qualitative data collection methods (pre-survey, journal writing with reflective prompts, focus groups, individual interviews, classroom observations, and post-survey).

Eight themes emerged from the analysis, namely (a) experiencing a language barrier, (b) experiencing what it feels like to be the minority in a society, (c) being exposed to cultural differences and experiencing culture shock, (d) perceiving differences in student participation and teaching methods, (e) adjusting classroom management, (f) underestimating English language learners, (g) building up confidence in teaching and instructional flexibility, and (h) learning to value support systems.

Overall, the participating teachers expressed some level of transformative learning regarding their teaching philosophy and cultural perspectives. They agreed that this foreign immersion project had not only advanced their global perspective, but had also equipped them with tools to provide a better learning experience to their culturally diverse students.

International immersion into co-teaching. A year later in 2011, the lead author conducted a second short-term international co-teaching experience for pre-service general education teachers who were paired up with intern special education teachers $(n=8)$ to provide English language instruction to young learners in South Korea (Oh et al., 2017) for two weeks. Thirty underserved Korean students ranging from grades 2 through 11 with mostly low levels of English speaking and listening skills participated in the 'English camp' and received English language instruction from these U.S.

Journal of the Scholarship of Teaching and Learning, Vol. 21, No. 3, October 2021. josotl.indiana.edu 
teachers. The majority of these Korean students would not normally have had such an opportunity due to their socioeconomic status.

Two administrative staff and a special education professor from the Korean university were liaisons. The U.S. teachers received initial classroom support (e.g., translation and interpretation) from Korean teaching assistants who were undergraduates at the Korean university's special education program. The narratives of two participating teachers from the U.S. were chosen for phenomenological analysis. Whereas one of the narratives reflects an overwhelmingly positive coteaching experience, the other recounts a rather unfavorable co-teaching experience in a foreign setting.

The main research focus was on the factors that make a co-teaching experience successful. These factors include open communication, receptiveness to both positive and negative feedback, the willingness to learn from someone who may have less teaching experience, mutual respect and trust, compatibility of personal characteristics, and frequent check-ins. Threats to a successful coteaching experience were identified as mismatched personalities, incompatible teaching goals, the lack of co-planning, conflicting approaches to lesson planning, unequal roles, infrequent check-ins, and a lack of trust and respect. In addition to analyzing and sharing their co-teaching experiences, the participating teachers also reflected on the impact of their immersion experience from a cultural perspective. Data collection included program application essays, daily self-reflection journals, oneon-one interviews, a group discussion, a post-survey, and a program evaluation. After gaining teaching experience in the U.S., one participant looked back on her teaching experiences in Korea and expressed some of the discrepancies she had noticed:

This impacts my daily teaching here in the U.S. because we just don't see that type of charisma and dedication for their learning (for most of our kids). Students here do not respect their teachers like those in Asian countries. Students here also take for granted the fact that they are given a free education. It's upsetting to me often times when I see the same students disrespecting their teachers or misusing their opportunities to learn. (Oh et al., 2017, p. 10)

Both studies documenting the two Korean projects mirrored what is identified in the literature, namely, that international immersion experiences offer a valuable platform to experience dissonance between one's own cultural frame of reference and another culture's frame of reference (Baecher \& Chung, 2020; Mezirow, 2003) and to enhance teachers' global perspectives (Malewski et al., 2012; Phillion \& Malewski, 2011).

\section{Methodology}

Context

This study was guided by two research questions:

1. What long-term impact does an international immersion experience have on teacher trainees in the U.S. with regard to their cultural responsiveness?

2. What long-term impact does an international immersion experience have on teacher trainees in the U.S. with regard to their teaching practice?

Journal of the Scholarship of Teaching and Learning, Vol. 21, No. 3, October 2021. josotl.indiana.edu 
Given the nature of these research questions, a case study methodology with an emphasis on inductive data analysis and an in-depth exploration of participants' perspectives (Mills et al., 2010) seemed to be an appropriate approach.

\section{Participants}

The lead researcher reached out to six female special education and general education teachers who had participated in one of two immersion projects conducted in South Korea in 2010 and 2011. The main goal was to capture if immersion in a foreign culture and the teaching of primary and secondary school students in South Korea had any sustainable impact on the participating teachers' perception of their culturally responsive teaching efficacy several years after their immersion experience (seven and eight years, respectively). Table 1 provides an overview of the participants who agreed to be interviewed for the present follow-up study.

Table 1. Participants.

\begin{tabular}{|c|c|c|c|c|c|c|}
\hline Pseudonyms & Ethnicity & Age* & $\begin{array}{l}\text { Teaching } \\
\text { Experience } \\
\text { (in years)* }\end{array}$ & Age** & $\begin{array}{l}\text { Teaching } \\
\text { Experience } \\
\text { (in years)** }\end{array}$ & $\begin{array}{l}\text { Teaching } \\
\text { Credential } \\
* * *\end{array}$ \\
\hline Sally & White & 27 & 1 & 35 & 9 & SPED \\
\hline Evelyn & White & 21 & 0 & 30 & 6 & Gen Ed \\
\hline Sandy & Asian & 26 & 1 & 35 & 9 & SPED \\
\hline Gina & White & 20 & 0 & 29 & 4 & Gen Ed \\
\hline
\end{tabular}

Although there were a total of 13 participating teachers in the two immersion projects described earlier, the interview request was only sent to six because these were the students who were still in contact with the lead author. The remaining seven individuals were not contacted because they have left the teaching field. Four participants, all of whom are still working as teachers in K-12, responded to the request and all four agreed to participate in a one-to-one interview via videoconference. It turned out that two of the six individuals who were contacted had also left the field of education.

\section{Data Collection}

Data for this study were collected through a semi-structured interview with the four participating inservice teachers and a questionnaire.

Teacher Interviews. The lead author conducted one-to-one interviews with the four teachers in November 2018. The main goal of the interviews was to determine whether the immersion experience (in 2010 and 2011, respectively) had a sustainable impact on the participants' teaching. The interview questions emerged from multiple sources. They emerged from the program evaluation of the first immersion project conducted in 2010 (Oh \& Nussli, 2014), from the review of the literature, from both authors' current teaching context, and from an informal two-year follow-up with the project participants. The semi-structured interviews were guided by nine questions:

1. You've already completed the self-assessment form, which is based on various elements of culturally responsive teaching. How would you define culturally

Journal of the Scholarship of Teaching and Learning, Vol. 21, No. 3, October 2021. josotl.indiana.edu 
Oh and Nussli

responsive teaching in your own words? Or, put differently, what does it take to be a culturally responsive teacher?

2. Please think about your short-term international immersion experience in South Korea in 2010 and 2011. How has this experience impacted your cultural responsiveness as a teacher?

3. Do you think you would teach differently if you didn't have this immersion experience? If so, in what way?

4. What was the most valuable cultural experience you had?

5. To which extent did the immersion experience help you build up the confidence to teach culturally diverse classes?

6. Can you think of examples of difficulties that your students with culturally diverse backgrounds have experienced? and follow-up: In what way were you able to help address these difficulties?

7. Have you seen students with culturally diverse backgrounds struggle with acclimating to the new environment in your classroom or at your school? and follow-up: Were you able to identify these students much more quickly than your colleagues and how were you able to help these students?

8. Can you think of examples of instances where your students had fun because your class is culturally diverse?

9. Do you have any advice to teacher trainees and novice teachers? More specifically, (1) What can they do to become culturally responsive teachers? (2) What should they avoid in this process? (3) How can they best accommodate the needs of all students in culturally and linguistically diverse classes?

Questionnaire. A 12-item questionnaire was modified from an existing scale about in-service teachers' self-efficacy beliefs regarding culturally responsive teaching practices (Chu \& Garcia, 2014). Responses were based on a 5-point Likert-type scale ranging from effectively, quite effectively, neutral, rather ineffectively to ineffectively. An additional response choice (don't know) was added. The questions are shown in Table 2 in the Result section. The questionnaire had multiple objectives, namely, to clarify the concept of culturally responsive teaching, to prompt reflection in the participants about what it means to them personally, to self-assess their culturally responsive teaching skills, and, not least, to prepare them for the interview. The questionnaire captures the teachers' perceptions of their skills in the following competencies of culturally responsive teachers: adapting activities and materials, creating a culturally responsive learning environment, using students' prior knowledge, using multiple means of assessment, critically examining the curriculum, identifying potential mismatches between students' behavior and communication at home and in school, and establishing positive relationships with students and their families and among students (Chu \& Garcia, 2014).

Procedures. Once the online interview was scheduled, the four teachers received the questionnaire by email. They were asked to complete the self-assessment questionnaire within a week prior to the interview. Next, the lead author conducted individual online interviews with the four teachers in November 2018. The teachers also received the interview questions seven days prior to the interview so they could prepare for the interview. All four interviews were conducted and recorded in Zoom, using audio-transcription for cloud recordings.

Researcher Reflexivity. As the qualitative researcher is often the primary instrument of data collection and analysis, reflexivity is crucial (Merriam \& Tisdell, 2016). Because the first author had also assumed the role of the immersion program coordinator in South Korea, continuous reflection on his role and the research relationship was particularly important. To provide a platform for researcher reflexivity and to help support the qualitative researcher's integrity, the second author

Journal of the Scholarship of Teaching and Learning, Vol. 21, No. 3, October 2021. josotl.indiana.edu 
conducted a written interview with the first author. This interview prompted him to reflect critically on his expectations prior to the immersion project, his biases, his role and involvement during the immersion, and his 'self' as a researcher (Lincoln \& Guba, 2000; Merriam \& Tisdell, 2016). The structured interview consisted of the following questions all of which revolved around the two immersion programs, which took place in 2010 and 2011:

1. To which extent were the objectives achieved at the time?

2. What were your values and expectations you brought to the study?

3. Did the immersion projects in South Korea turn out as expected?

4. What was unexpected?

5. Which obstacles were encountered?

6. Were there any positive surprises?

7. In hindsight, what should be modified to improve an international immersion project regarding the preparation phase, during-phase, and post-phase?

8. In conclusion, from the researcher's perspective: To which extent and how can international immersion help develop cultural responsiveness in teachers?

9. How have your values and expectations influenced the conduct and conclusions of the study?

The program coordinator's full answers to the interview questions are shown in Appendix 1.

\section{Data Analysis}

Qualitative Data. The qualitative data emerged from the live interviews with four teachers. The interview transcripts were analyzed qualitatively using thematic analysis. The themes were identified in a five-stage process, namely, familiarizing with the data, generating initial codes through open coding, identifying themes, merging and collapsing codes, and reviewing and naming themes (Creswell, 2013; Merriam \& Tisdell, 2016). It was ensured that the categories constructed during data analysis meet certain criteria, namely, that they are responsive to the purpose of the research and as sensitive to the data as possible (Merriam \& Tisdell, 2016). The second author, who had not been involved in the immersion projects, analyzed the data. MaxQDA (2019) was used for coding, coding comparisons, and generating frequencies. Although the focus was on identifying themes across participants, the authors purposefully screened the data for atypical responses. The total duration of the interviews with the teachers was 105 minutes and ranged from 18 to 35 minutes each. The total word count of the transcribed interviews was 9,786 words and ranged from 1,469 to 4,169 words.

Quantitative Data. The 12-item questionnaire was adopted from Chu and Garcia (2014). From the original 20-item scale designed to measure in-service teachers' culturally responsive teaching efficacy beliefs, 12 items were retained for this study. Selection of the items was based on the items' immediate relevance to the interviewees' teaching practice and the ways they have been implementing culturally responsive teaching approaches in their own classrooms ever since their immersion experience. Frequencies were calculated for each response choice. Given that the main purpose of the questionnaire was to prepare the participants for the interviews, there was no need for further analysis.

\section{Results}

The themes that emerged from the inductive analysis of the interview data provide answers to the two research questions, namely, the impact of an international immersion experience on teacher

Journal of the Scholarship of Teaching and Learning, Vol. 21, No. 3, October 2021. josotl.indiana.edu 
trainees in the U.S. with regard to their perception of their own cultural responsiveness and their current teaching strategies. Four interrelated themes emerged from the analysis of the interviews with the participating teachers, namely, perspective taking, relationship, teaching skills, and cultural knowledge. Representative statements substantiating each of the themes and codes will now be presented.

\section{Theme 1: Perspective Taking}

Notice, respect and understand different values. When reflecting on their immersion experiences in Korea, the interviewees' narratives indicated that they had become aware of different values, such as parents' varying perceptions of the value of education. Experiencing different values in Korea (where education is being highly valued) helped them become more aware of values that may differ across cultures:

So something I struggled with as a teacher from the very beginning was, I don't understand why you guys don't have the same values.

And kind of adjusting on the fly to those cultural differences that are unexpected that you just, oh, I wouldn't even think that that would be something to talk about or something that I would need to address or a conversation that needs to be had.

Ability to take a different perspective. The immersion experience also indicated that the participants were more willing and more skilled in taking someone else's perspective, for example, what it feels like if the cultural conventions (i.e., in Korea) prevent students from asking the teacher questions in class because this would be considered inappropriate and impolite. Understanding these differences helps teachers modify their approaches so that all students can contribute in a way they feel comfortable with:

Right, so there they know how to do the math, but they don't understand like the social situation, or they don't know how to make the food that they're talking about, or they don't have any kind of like image in their mind of what the thing is.

I think about them often because they would pretend like they would understand. They're not supposed to ask questions.

You just have a little more understanding that not everybody does the same thing everybody else does.

So I think it just gave me a different perspective, but I don't know that really changed how I teach, I think I've remained pretty consistent in how I teach, but it definitely just gave me a different lens to look through.

Show empathy toward different behavior and perspective. The immersion experience caused the participating teachers to experience what it feels like when one does not speak the language. Being unable to understand and communicate in Korea increased their sympathy toward English language learners in the US:

But those kinds of things make a huge difference in the way you treat other people when they're in a culture that they're not familiar with, like, you give them a little more grace.

It was like a disaster. I'm like, no directions or even any like basic phrases. And that's really the one I felt like the most. Um, this is really what language learners' experience. And so they were in our school system for the first time and figuring out the language.

Journal of the Scholarship of Teaching and Learning, Vol. 21, No. 3, October 2021. josotl.indiana.edu 
Exposure to differences. Experience a dissonance between their own frame of reference and others' frames of reference ("seeing how that part of the culture was different from what I'm used to") was an eye-opening experience and helped them become more aware of student behavior that may differ due to cultural norms, for example, regarding communicative styles:

I also think you know the difference in the behavior of a lot of the students when they didn't know what was going on. The students were just much more quiet and whereas the cultures that I had more exposure to in California. When students didn't know what was going on. It was more like disruptive behavior as opposed to kind of that internalized quiet response to not knowing what's going on.

Differences in conversation culture... Like, I know you know some of my students that I had when I was in the classroom. It was very culturally appropriate for them to be talking over one another.

\section{Theme 2: Relationship}

Reach out to families and the community. All participants emphasized the importance of reaching out to the families and showing interest in the community, for example, by going to different events "to get to know the people who are important in the community". They felt that it was "definitely worth it to research on reach out to your students and their families, learn about them and try to make as many connections with them as you can."

Establish relationship with parents. All participants emphasized the critical need to establish positive relationships with parents and understand how the parents' perceptions of school translate to the students' behavior and affective levels in school:

And really being open to having conversations with parents and students about their backgrounds but knowing that sometimes it really takes time depending on the culture for people to feel comfortable opening up.

Yeah, because if the parents have like this fear of the system, or they feel like they're excluded in some way, then even if they tell their kids that school is important, something that they value, I think the kids can, you know, they can see that discomfort and that translates into the classroom.

Know your students. All participants emphasized multiple times that to build trust it is crucial to invest the time to get to know the students, listen to them, and making a real effort to understand them and their history:

So yeah, I do try to be mindful about those things that I know that they are experiencing in their own homes or in their own communities.

Same thing just understanding who that kid is deep down, and where they're coming from.

Build trust. Building the parents' trust was also emphasized multiple times, along with the positive impact for the students. The participants expressed that the time invested in building a trustworthy relationship with the parents would ultimately benefit the student:

So I always just, you know, would say to parents as much as you're willing to tell me is really helpful for me. And I can keep that information to myself or I can share it with your child.

Journal of the Scholarship of Teaching and Learning, Vol. 21, No. 3, October 2021. josotl.indiana.edu 
You know the rest of your child's teachers and I found that over time families who initially were really hesitant to maybe share difficult information or you know, more personal information more and more of that came out as time went on, and it really did have a positive effect for the student.

Establish better connection with students. The participants agreed that having experienced cultural immersion helped them understand the critical importance of a positive relationship with the student. They made it clear that having a good connection with every single student was their top priority. One of the ways to establish this connection is to show real interest in events that happen in their students' lives:

And then, and when I bring up stuff about their families or little things that they might think that I don't remember they said, or that they told me or shared with me. I think just building relationships with those kids is number one in my mind.

I can't be successful with every kid. But if every kid leaves my room, knowing that I care about them, that's, that's really most important to me.

Change way to talk to students and parents. It was mentioned that having experienced cultural immersion themselves made them more responsive to cultural differences in communication:

It affects how I talked to the kids.

It makes a huge difference in me as a teacher in the way I talked to my students, in the way I teach.

It definitely changes the way I talk to families more than anything else.

Theme 3: Teaching Skills

Make accommodations for students. All participants mentioned that they are making cultural accommodations for students based on their family and background, that they use interventions and teaching practices that are sensitive to different cultures. They referred back to their teaching experience in Korea and to the flexibility needed at the time to accommodate students' needs, to reevaluate and adjust their teaching strategies, and to consider what could be changed to make their teaching more useful for the Korean students. Once they became aware of the need for cultural adjustments, they were able to incorporate them into their classroom both in the U.S. and in Korea:

To share that that teacher goes a step further and does research about it and brings those aspects of the culture that are relevant to their students into the classroom and really honors them.

And just from like different strategies that were helpful in Korea. Um, I think using those strategies in my classroom that really impacted my teaching. I work really hard to bring in like materials, whether it's text or images or videos that reflect the different cultures and different backgrounds and my kids are coming from.

Setting up even setting strict policies and then realizing, oh, maybe that's not actually going to work for the students that I have in this classroom. So being a little bit flexible as well.

Becoming a better teacher for the students. The participants agreed that the immersion experience really helped them understand how to be a better teacher for their students. In discussing how to

Journal of the Scholarship of Teaching and Learning, Vol. 21, No. 3, October 2021. josotl.indiana.edu 
offer more effective teaching to the Korean students, they were able to identify ways to help them in the best possible way:

Give your best for that day and then you reevaluate at the end of the day and say, okay, what worked, what didn't work. How can we do better kind of thing. And that process, I mean, the Korea trip made a big difference in that.

Building self-confidence. The teaching experience in Korea required maximal flexibility from the participating teachers because they had never worked with Korean students before. Although they had prepared activities and lesson plans beforehand, they did not know what grade level there were going to teach and how much or how little English their students knew until after they arrived in Korea. They needed to change teaching strategies and activities practically over night in order to better accommodate the students. Experiencing that they were able to accomplish this task, in collaboration with their peers and co-teachers, helped them build up their self-confidence as teachers:

I think being immersed in a culture was really valuable and that I had made some positive difference in their life. That was huge. So just knowing that I could do that.

I think that, on the fly, kind of experience builds confidence really quickly because the kids enjoyed it. They did learn, you could see the progress, even in such a short amount of time with them.

Like it made me rely on my skills that I knew how to teach right like I know what I'm doing. I mean, it definitely builds confidence because when you come across those things in the lesson. You have to know what you're doing enough to be able to just make the change.

Yeah, I mean, it's hard enough just to do that in the U.S. as a beginning teacher, but you had to go and do it in a different country with, you know, different language and culture so I think it's kind of like sink or swim, swimming in the deep end.

\section{Theme 4: Cultural Knowledge}

Cultural knowledge and wrong assumptions. All participants mentioned the risk of jumping to conclusions due to stereotyping. They all recommended that teachers should avoid assumptions about the way that children are and they should listen to them instead. Similarly, teachers need to be aware of their own culture and their own biases:

I'm something that happens really often people like to stereotype. Oh, this family like does this because they're from this country. This is how that kids going to be like and you just can't do that. I mean, you've got to listen to that kid specific background, just because they look Asian doesn't mean that they're like Chinese.

Cultural understanding. In terms of affecting their teaching, the immersion experience gave them more exposure to different types of cultures. Being immersed in a culture helped them learn about it and use that information to inform their teaching approaches. They agreed that any sort of immersion experience has the potential to broaden their views of different types of people and different ideas, which would ultimately transfer to their own teaching back in the U.S.. For example, being knowledgeable about the role that culture plays in school can have a considerable impact on classroom management.

Journal of the Scholarship of Teaching and Learning, Vol. 21, No. 3, October 2021. josotl.indiana.edu 
And that was something that I kind of had to learn and understand that they weren't trying to be disrespectful. But that was something that, you know, and particularly in African American culture that's very acceptable.

Figure 1 provides a visual summary of the themes and codes that emerged from an inductive analysis of the interviews.

Themes from Teacher Interviews

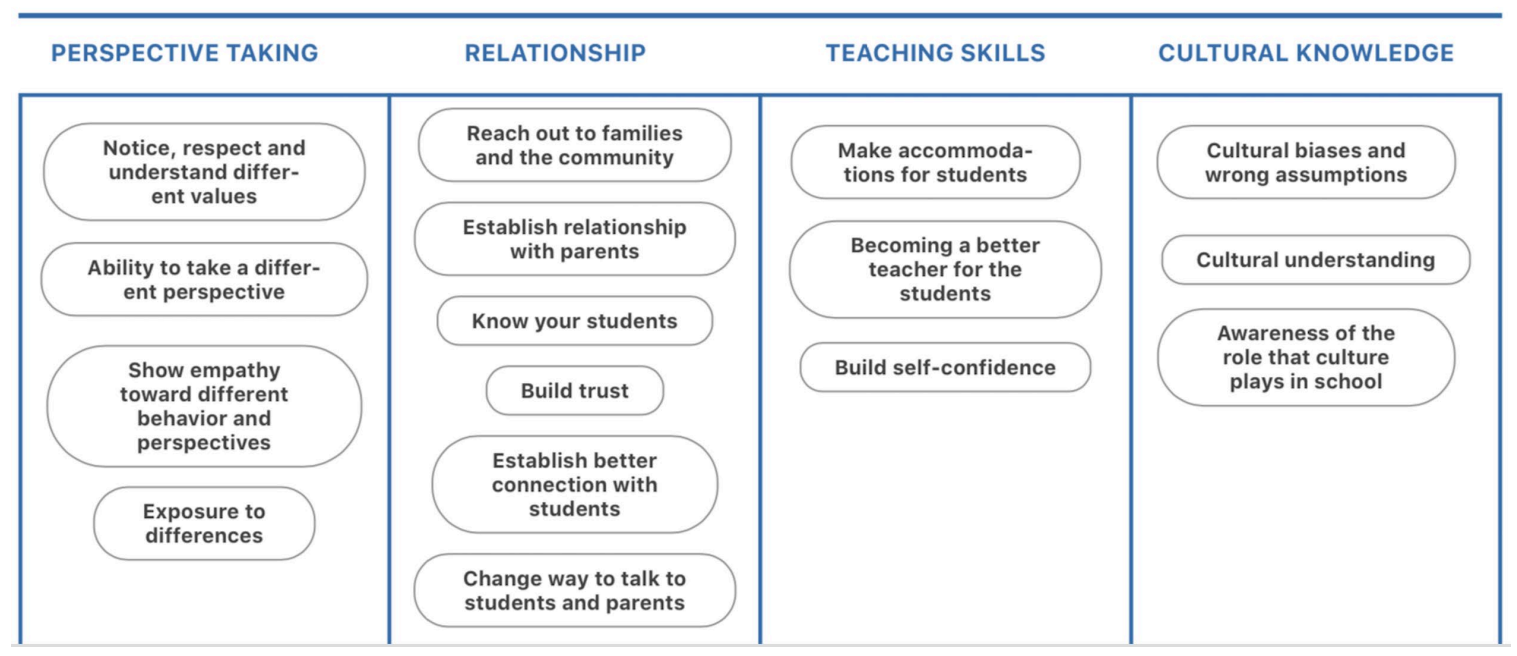

Figure 1. Themes and codes from teacher interviews.

\section{Atypical Responses}

The transcripts of the teacher interviews were purposefully screened for atypical answers, although it was challenging with such a small sample. It was found that the statements of the four teachers aligned very well with each other, probably because their experiences during the immersion trip were similarly positive. No atypical answers were identified.

\section{Teachers' Perceptions of their Self-Efficacy in Culturally Responsive Teaching}

The results of the questionnaire (Table 2), which was administered to the participating teachers in preparation for the interview, show that the participants rated their self-efficacy regarding culturally responsive teaching as effective $(46 \%)$ or quite effective (44\%). Only $10 \%$ of the answers were found in the neutral category, thus indicating a rather high level of self-efficacy overall. None of the respondents rated their self-efficacy as either rather ineffective or ineffective, and no one chose don't know for any of the 12 items. 
Table 2. Culturally responsive teaching self-efficacy (adapted from Chu \& Garcia, 2014).

\begin{tabular}{|c|c|c|c|c|c|c|c|}
\hline & I am able to... & $\begin{array}{c}\text { Effecti } \\
\text {-vely }\end{array}$ & $\begin{array}{l}\text { Quite } \\
\text { effect } \\
\text { i-vely }\end{array}$ & $\begin{array}{c}\mathrm{Ne} \\
\text { utr } \\
\text { al }\end{array}$ & $\begin{array}{l}\text { Rather } \\
\text { ineffec } \\
\text {-tively }\end{array}$ & $\begin{array}{l}\text { Inef } \\
\text { fec- } \\
\text { tivel } \\
\text { y }\end{array}$ & $\begin{array}{l}\text { Do } \\
\text { n't } \\
\text { kn } \\
\text { ow }\end{array}$ \\
\hline 1 & $\begin{array}{l}\text { modify instructional activities and materials to meet the } \\
\text { needs and learning interests of my culturally diverse } \\
\text { students. }\end{array}$ & 2 & 2 & & & & \\
\hline 2 & $\begin{array}{l}\text { create a learning environment that reflects the various } \\
\text { backgrounds of my culturally diverse students. }\end{array}$ & & 4 & & & & \\
\hline 3 & $\begin{array}{l}\text { use my students' prior knowledge related to their } \\
\text { cultural and linguistic backgrounds to help make } \\
\text { learning meaningful. }\end{array}$ & 1 & 3 & & & & \\
\hline 4 & $\begin{array}{l}\text { use various types of assessment that is matched to } \\
\text { English language learners' language proficiency. }\end{array}$ & 2 & 1 & 1 & & & \\
\hline 5 & $\begin{array}{l}\text { critically examine the curriculum to determine whether } \\
\text { it appropriately represent culturally diverse groups. }\end{array}$ & 2 & 1 & 1 & & & \\
\hline 6 & $\begin{array}{l}\text { identify the differences between student } \\
\text { behavior/communication at home and student } \\
\text { behavior/communication at school. }\end{array}$ & & 3 & 1 & & & \\
\hline 7 & $\begin{array}{l}\text { use a variety of teaching methods to assist my students } \\
\text { in learning the content. }\end{array}$ & 1 & 2 & 1 & & & \\
\hline 8 & $\begin{array}{l}\text { implement interventions that minimize the effects of } \\
\text { cultural mismatch between home and school. }\end{array}$ & 1 & 2 & 1 & & & \\
\hline 9 & $\begin{array}{l}\text { distinguish cultural differences from learning difficulties } \\
\text { for culturally diverse students. }\end{array}$ & 2 & 2 & & & & \\
\hline 1 & create a caring, supportive, and warm learning & 4 & & & & & \\
\hline 0 & environment for my culturally diverse students. & & & & & & \\
\hline 1 & build positive relationships with parents of culturally & 3 & 1 & & & & \\
\hline 1 & diverse students. & & & & & & \\
\hline 1 & help my culturally diverse students develop positive & 4 & & & & & \\
\hline 2 & interactions with each other. & & & & & & \\
\hline & Total & $\begin{array}{c}22 \\
(46 \%)\end{array}$ & $\begin{array}{c}21 \\
(44 \% \\
)\end{array}$ & $\begin{array}{c}4 \\
(10 \\
\%)\end{array}$ & - & - & - \\
\hline
\end{tabular}

\section{Discussion}

This follow-up study investigated the long-term impact of an international immersion experience on U.S. American teacher trainees with regard to their cultural competence and their teaching practices. The participants' statements during the interviews indicated that the short-term immersion experience has broadened their views of different cultures and helped them refine and adjust their teaching practices. Specifically, the immersion experienced enhanced their awareness of culturally different perspectives on schooling, the critical need for parent involvement and family engagement, their mindfulness of students' origins, and their awareness of culturally relevant textbooks and resources that the children can connect to. The immersion experience also enhanced their sensitivity toward the struggles that culturally diverse students might experience. The participants consistently reported that the immersion experience has helped them develop better knowledge of what it takes to build up a trusting relationship with all students, regardless of their cultural or linguistic background. 
The themes that emerged from the interview data revolved around perspective taking abilities; establishing relationship with students, parents, and their communities; the development of teaching skills; and cultural knowledge. As discussed in Abacioglu et al. (2019), perspective taking ability is among the key qualities of a culturally responsive teaching approach. The participants in the present study frequently referred to their own negative stereotyping and sets of assumptions that were deconstructed during their immersion experience in order to build new principles and values, which indicates transformative learning (Acquah \& Szelei, 2020; Mezirow, 2003).

Due to their first-hand experience in Korea, they reported having more empathy toward English language learners because they had experienced themselves what it feels like not knowing the language. Being unable to communicate in the local language might be compared to what Trilokekar and Kukar (2011) identified as "experience outsider status" (p. 1145), which is one of four categories for examining teacher candidates' disorienting experiences during international immersion.

Honoring cultural differences and appreciation of students' individual backgrounds emerged as important markers of the participating teachers' beliefs. Similar to the descriptions in Acquah and Szelei (2020), the four teachers expressed a caring attitude and demonstrated an affirming attitude to build on their students' linguistic and cultural strengths, which echoes previous research (Barba et al., 2019; Gay, 2010; Ladson-Billings, 1995; Villegas \& Lucas, 2002). They emphasized the importance of making cultural accommodations, for example, by challenging existing instructional materials and by adapting instruction and learning resources to better serve the students' needs (Abacioglu et al., 2019; Acquah \& Szelei, 2020; Chu \& Garcia, 2014; Darling-Hammond, 2000; Gay 2010; McAllister \& Irvine, 2002), which are core principles of culturally responsive teaching.

The participants' statements indicated that they embrace multiple competencies associated with culturally responsive teaching. They made frequent references to strategies that were used in Abacioglu et al.'s (2019) scale of culturally sensitive teaching (modified from Siwatu, 2007), such as using the students' cultural background to make learning meaningful, obtaining information regarding the students' cultural background, revising educational materials to better represent cultural diversity, obtaining information about students' interest, and identifying differences between the child's home culture and the school culture that children are struggling with.

Although the findings indicate that the short-term teaching experiences in Korea had a sustainable impact on the four participating interviewees regarding their cultural knowledge, competence, and awareness, there are a number of limitations regarding this study, which will be discussed next.

\section{Limitations}

Regarding the interviews, it is possible that the participating interviewees may have felt obligated to share more of their positive experiences during the interview because the interviewer was also leading the project at the time. Another potential limitation could be that the interviewer was a male faculty member and all of the participants were females; thus, they may have not felt comfortable talking about some of the struggles they experienced. The four interviewees were not only more vocal during the trip to Korea than other teachers participating in the immersion project, but they also had more positive things to say at the end of their immersion experience, which could explain why they volunteered for the interview in 2018.

Some of the interviewees might have re-read their reflective journals just before the interview, which could have influenced the way they responded to the interview questions and thus might limit internal validity to some extent. The small sample size is clearly a limitation. A multi-year case-study approach similar to Malewski et al. (2012) with multiple cohorts of teachers would have

Journal of the Scholarship of Teaching and Learning, Vol. 21, No. 3, October 2021. josotl.indiana.edu 
generated more data. For future studies, follow-up interviews should be conducted with a more systematic and focused approach and should include all participating teachers rather than a small sample. Follow-up interviews should be held more than once and at regular intervals (e.g., every two years). Although the lead author contacted all eight teachers from the 2011 Korea project two years later in 2013, this was only an informal follow-up request to learn how the Korean co-teaching experience had shaped their teaching practices in the U.S. Four teachers responded at the time. Because the interviews in 2018 were conducted after a rather long period of time, it was too late to interview those participants who had left the teaching profession.

\section{Conclusions}

The purpose of this study was to explore whether the immersion abroad had any sustainable effects on teachers participating in a short-term immersion experience nearly a decade earlier and how this experience has helped them become culturally competent teachers. While the findings provide insight into four teachers' cultural knowledge, competence, and awareness and the ways they connect their current teaching approaches back to their short-term immersion experiences in South Korea, it is impossible to measure the exact impact of the immersion experience. Their beliefs could have further evolved due to other reasons, such as professional development courses, traveling, teaching experience in culturally heterogeneous classes, dialogues with teacher colleagues, or any other encounters with cultural diversity. It is also debatable whether these four teachers experienced true transformative learning as a result of a short-term immersion program in Korea. Their answers indicate that they had multiple eye-opening experiences and that these illuminating experiences had a sustainable impact on how they now interact with their students, how they reach out to their families and communities, and which aspects to be mindful of when making cultural adjustments to their instruction.

\section{Implications for Teacher Educators}

Teacher educators must examine how their course content and presentation formats influence preand in-service teachers' skills and their schemata about teaching and learning. Due to the increased heterogeneity of future student populations, it is essential for teachers to receive intercultural training and be given ample opportunities to reflect on ways to become culturally responsive teachers. Through service and immersion projects, teachers can better meet the needs of all of their future students, regardless of their cultural or linguistic background.

\section{Future Research}

Future research should explore how teachers' implicit rules of their own culture shape their classroom teaching (Malewski et al., 2012) and if an immersion experience abroad might bring about change. More follow-up studies should be conducted to capture whether immersion trips have any long-term impact on teachers' approaches to culturally responsive teaching practices. Once the participating teachers have several years of teaching experience, they can be asked to assist with the design of future immersion programs for teacher candidates. They could provide valuable help in identifying the most effective components of immersion programs that had a sustainable impact on their own teaching.

Another avenue for investigation could be how co-teaching experiences abroad could maximize teachers' cultural learning. For example, pre-service teachers offering co-teaching instruction abroad can observe their co-teachers' displays of cultural sensitivity toward students.

Journal of the Scholarship of Teaching and Learning, Vol. 21, No. 3, October 2021. josotl.indiana.edu 
They can engage in co-reflection, provide intentional peer support, and share strategies with each other.

International field experiences may also offer new pathways for helping teachers "deconstruct their assumptions about meritocracy, educational equity, and school achievement" (Lazar \& Sharma, 2016, p. 122). By utilizing teachers' feelings of discomfort and experiences of cultural dissonance when being immersed in a foreign culture, new understandings of cultural values and different pedagogical practices might be created (Sharma et al., 2012).

\section{Appendix}

\section{Appendix 1. Full Interview with Program Coordinator (lead author).}

Q1: To which extent were the objectives achieved at the time (i.e., in 2010 and 2011)?

The main objective of the projects was to provide an inclusive and culturally relevant experience to both groups. Initially, both groups (students and teachers) needed time to build rapport, but once they built relationships and trust, it was difficult for them to not engage in academic and life experiences.

Q2: What were your values and expectations you brought to the study?

As an immigrant to the U.S. from Korea myself, I was able to provide services to the groups (teachers, students, administrative team in Korea) that others may not be able to do. For example, I was the team translator, tour guide, counselor, and cultural expert to name a few. Understanding both cultures provided an easy path to complete these roles.

\section{Q3: Did the immersion projects turn out as expected?}

I did have high expectations for both programs. I was hoping that the teachers were better prepared to teach the students in Korea, but I believe the struggles we faced (language, culture, preparation teaching materials, etc.) were good for the individual teachers and the team. The growth I saw as the coordinator was very rewarding. When the teachers shared how much they have learned about the importance of cultural understanding between teachers and students in South Korea, I realized that the gap of knowledge between these two groups actually helped in this situation.

\section{Q4: What was unexpected?}

I did not have a strong understanding of how the students in Korea were going to be toward our program and especially teachers. One of the students was so shy that I had to do a one on one lesson with her. I think the shyness came out due to the fact that this student had the lowest English ability.

\section{Q5: Which obstacles were encountered?}

The schedule during the trip changed multiple times due to unforeseeable matters, but I did prepare everyone in the team from the U.S. that we need to be very flexible once we are in Korea. For example, some of the outings were delayed due to the bus coming later than scheduled.

\section{Q6: Were there any positive surprises?}

Some of the teachers bonded really well with the teacher aides and they went out on outings on their own. The friendships they built while teaching together and those outings were surprising to me.

Journal of the Scholarship of Teaching and Learning, Vol. 21, No. 3, October 2021. josotl.indiana.edu 
Q7: In hindsight, what should be modified to improve an international immersion project regarding the preparation phase, during-phase, and post-phase?

Preparation phase: providing more cultural background of the students in Korea, printing and bringing more teaching materials. During: recording the teaching and providing time for them to reflect. Post: We should have had 6-month-, 1-year, and 2-year reunion dinners.

Q8: How have your values and expectations influenced the conduct and conclusions of the study?

I always wanted to give back to my home country after I immigrated to U.S. This was one way that I, as a teacher trainer, could provide to the children in South Korea who are not as fortunate to attend a summer English camp due to financial constraints of their parents. I shared my appreciation for the teachers' work at the end of the trip get-together and I hope that they felt good about being part of this project.

Q9: In conclusion, from the researcher's perspective: To which extent and how can international immersion belp develop cultural responsiveness in teachers?

I strongly believe that teachers need to experience what immigrant students have to endure in their first month of relocating. This type of trips provides a first-hand experience in language struggle and culture shock that cannot be understood without these teachers facing it directly. I would like to do similar projects in other countries. My lifetime goal is to bring teachers to Korea when it reunifies and do something similar in the North Korea side of the country. I would have liked to connect preservice teachers in Korea with my students in the U.S. before the departure so that the relationships were built before we arrived.

\section{References}

Abacioglu, C. S., Volman, M., Fischer, A. H. (2019). Teachers' multicultural attitudes and perspective taking abilities as factors in culturally responsive teaching. British Journal of Educational Psychology, 1-17. https://bpspsychub.onlinelibrary.wiley.com/doi/10.1111/bjep.12328

Acquah, E. O., \& Commins, N. L. (2017). Methods that matter in addressing cultural diversity with teacher candidates. Teaching in Higher Education, 22(5), 501-518.

Acquah, E. O., \& Szelei, N. (2020). The potential of modelling culturally responsive teaching: preservice teachers' learning experiences. Teaching in Higher Education, 25(2), 157-173. https://doi.org/10.1080/13562517.2018.1547275

Baecher, L., \& Chung, S. (2020). Transformative professional development for in-service teachers through international service learning. Teacher Development, 24(1), 33-51. https://doi.org/10.1080/13664530.2019.1682033

Barba, Y. C., Newcombe, A., Ruiz, R., \& Cordero, N. (2019). Building bridges for new immigrant students through asset-based consultation. Contemporary School Psychology, 23, 31-46. https://doi.org/10.1007/s40688-018-00212-1

Chu, S. Y., \& Garcia, S. (2014). Culturally responsive teaching efficacy beliefs of in-service special education teachers. Remedial and Special Education, 35(4), 218-232.

Creswell, J. W. (2013). Qualitative inquiry and research design: Choosing among five Approaches (3 ${ }^{\text {rd }}$ ed.). Sage.

Darling-Hammond, L. (2000). How teacher education matters. Journal of Teacher Education, 51, 166173. https://doi.org/10.1177\%2F0022487100051003002

Gay, G. (2013). Teaching to and through cultural diversity. Curriculum Inquiry, 43(1), p. 48-70.

Journal of the Scholarship of Teaching and Learning, Vol. 21, No. 3, October 2021. josotl.indiana.edu 
Gay, G. (2018). Culturally responsive teaching: Theory, research, and practice. Teachers College Press, Columbia University.

Gay, G. (2000). Culturally responsive teaching: Theory, research, and practice. Teachers College Press, Columbia University.

Hammond, Z. (2014). Culturally responsive teaching and the brain: Promoting authentic engagement and rigor among culturally and linguistically diverse students. Corwin.

Kambutu, J., \& Nganga, L. W. (2008). In these uncertain times: Educators build cultural awareness through planned international experiences. Teaching and Teacher Education, 24, 939-951.

Keengwe, J. (2010). Fostering cross cultural competence in preservice teachers through multicultural education experiences. Early Childhood Education Journal, 28, 197-204.

Ladson-Billings, G. (1995). Toward a theory of culturally relevant pedagogy. American Educational Research Journal, 32(3), 465-491.

Ladson-Billings, G. (2009). The dreamkeepers: Successful teachers for African-American children (2 ${ }^{\text {nd }}$ ed.). Jossey-Bass.

Lazar, A., \& Sharma, S. (2016). "Now I look at all the kids differently": Cracking teacher candidates' assumptions about school achievement in urban communities. Action in Teacher Education, 38(2), 120-136.

Lincoln, Y. S., \& Guba, E. G. (2000). Paradigmatic controversies, contradictions, and emerging confluences. In N. K. Denzin \& Y. S. Lincoln (Eds.), Handbook of qualitative research ( $\left.{ }^{\text {nd }} \mathrm{ed}.\right)$ (pp. 163-188). Sage.

Mahon, J., \& Cushner, K. (2002). The overseas student teaching experience: Creating optimal culture learning. Multicultural Perspectives, 4(3), 3-8. https://doi.org/10.1207/S15327892MCP0403 2

Malewski, E., Sharma, S., \& Phillion, J. (2012). How international field experiences promote crosscultural awareness in preservice teachers through experiential learning: Findings from a sixyear collective case study. Teachers College Record, 114(8), 1-44.

Maynes, N., \& Allison, J., \& Julien-Schultz, L. (2012). International practica experiences as events of influence in a teacher candidates' development. McGill Journal of Education, 47(1), 69-92.

McAllister, G., \& Irvine, J. J. (2002). The role of empathy in teaching culturally diverse students: A qualitative study of teachers' beliefs. Journal of Teacher Education, 53, 433-443.

Merriam, S. B., \& Tisdell, E. J. (2016). Qualitative research: A guide to design and implementation (4 $4^{\text {th }}$ ed., The Jossey-Bass higher and adult education series). Jossey-Bass, A Wiley Brand.

Mezirow, J. (2003). Transformative learning as discourse. Journal of Transformative Education, 1(1): 5863.

Mills, A. J., Durepos, G., \& Wiebe, E. (2010). Encyclopedia of case study research. Sage.sichp]

Moskowitz, G. B. (2005). Social cognition. Guilford Press.

Muñiz, J. (2019). Culturally responsive teaching: A 50-state survey of teaching standards. New America.

Oh, K., Murawski, W., \& Nussli, N. (2017). An international immersion into co-teaching: A wake-up call for teacher candidates in general and special education. The Journal of Special Education Apprenticeship (JOSEA), 6(1), Article 2. https://scholarworks.lib.csusb.edu/josea/vol6/iss1/2/

Oh, K., \& Nussli, N. (2014). Challenging, eye-opening, and changing. U.S. teacher training in Korea: Creating experiences that will enhance global perspectives. Journal of the Scholarship of Teaching and Learning, 14(4), 67-87.

Phillion, J., \& Malewski, E. (2011). Study abroad in teacher education: Delving into cultural diversity and developing cultural competence. Action in Teacher Education, 33(5-6), 643-657. https://doi.org/10.1080/01626620.2011.627310

Journal of the Scholarship of Teaching and Learning, Vol. 21, No. 3, October 2021. josotl.indiana.edu 
Rodriguez, E. (2011). What pre-service teachers bring home when they travel abroad: Rethinking teaching through a short international immersion experience. Scholar-Practitioner Quarterly, 5(3), 289-305.

Rychly, L., \& Graves, E. (2012). Teacher characteristics for culturally responsive pedagogy. Multicultural Perspectives, 14(1), 44-49. https://doi.org/10.1080/15210960.2012.646853

Sharma, S., El-Atwani, K., Rahatzad, J., Ware, J., Phillion, J., \& Malewski, E. (2012). How disorienting experiences in informal learning contexts promote cross-cultural awareness in preservice teachers: Findings from a study abroad program. LEARNing Landscapes, 5(2), 281 294.

Shedrow, S. J. (2017). Cross-cultural student teaching: Examining the meaning-making of one white, female, middle-class preservice teacher. Journal of International Students, 7(2), 270-290.

Siwatu, K. O. (2007). Preservice teachers' culturally responsive teaching self-efficacy and outcome expectancy beliefs. Teaching and Teacher Education, 23, 1086-1101.

Trilokekar, R. D., \& Kukar, P. (2011). Disorienting experiences during study abroad: Reflections of pre-service teacher candidates. Teaching and Teacher Education, 27, 1141-1150.

Trumbull, E., Greenfield, P. M., Rothstein-Fisch, C., \& Quiroz, B. (2007). Bridging Cultures® in parent conferences: Implications for school psychology. In G. B., Esquivel, E. C. Lopez, S. G. Nahari (Eds.), Handbook of multicultural school psychology: An interdisciplinary perspective (pp. 615-636). Lawrence Erlbaum Associates Publishers.

Vavrus, M. (2008). Culturally responsive teaching. In T. L. Good (Ed.), 21st Century Education: A Reference Handbook (Vol. 2) (pp. 49-57). Sage Publishing.

Villegas, A., \& Lucas, T. (2002). Preparing culturally responsive teachers: Rethinking the curriculum. Journal of Teacher Education, 53, 20-32.

Walters, L. M., Garii, B., \& Walters, T. (2009). Learning globally, teaching locally: Incorporating international exchange and intercultural learning into pre-service teacher training. Intercultural Education, 20(1), 151-158. https://doi.org/10.1080/14675980903371050

Warren, C. A. (2018). Empathy, teacher dispositions, and preparation for culturally responsive pedagogy. Journal of Teacher Education, 69, 169-

183. https://doi.org/10.1177\%2F0022487117712487

Journal of the Scholarship of Teaching and Learning, Vol. 21, No. 3, October 2021.

josotl.indiana.edu 